\title{
Relative inequalities in geographic distribution of health care resources in Kermanshah province, Islamic Republic of Iran
}

\author{
S. Rezaei, ${ }^{1}$ A.K. Karyani, ${ }^{2}$ R. Fallah ${ }^{3}$ and B.K. Matin ${ }^{1}$
}

$$
\begin{aligned}
& \text { عدم المساواة النسبية في التوزيع الجغر افي لموارد الرعاية الصحية في محافظة كرمنشاه بجممهورية إيران الإسلامية }
\end{aligned}
$$

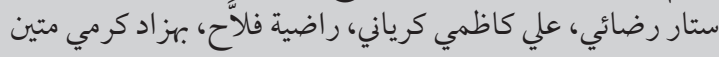

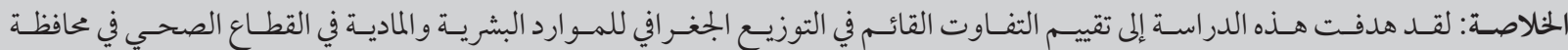

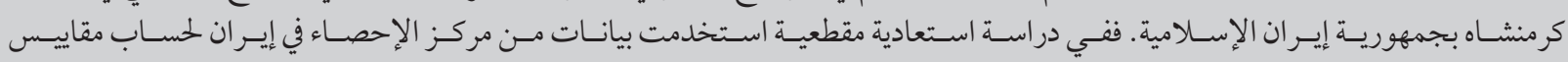

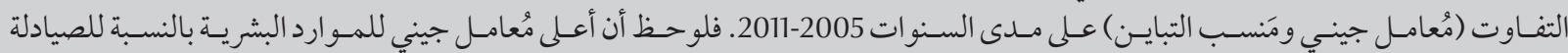

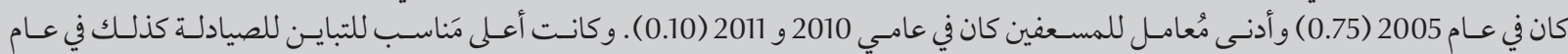

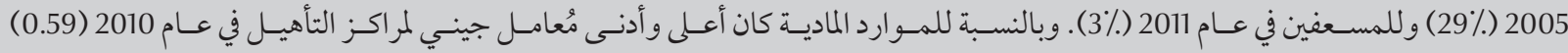

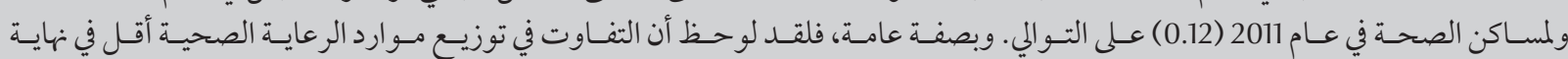

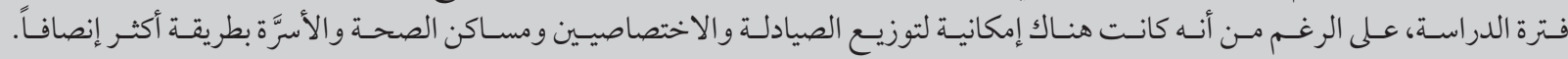

ABSTRACT This study aimed to evaluate inequalities in the geographical distribution of human and physical resources in the health sector of Kermanshah province, Islamic Republic of Iran. In a retrospective, cross-sectional study, data from the Statistical Centre of Iran were used to calculate inequality measures (Gini coefficient and index of dissimilarity) over the years 2005-11. The highest Gini coefficient for human resources was observed for pharmacists in 2005 (0.75) and the lowest for paramedics in 2010 and 2011 (0.10). The highest indices of dissimilarity were also for pharmacists in 2005 (29\%) and paramedics in 2011 (3\%). For physical resources, the highest and lowest Gini coefficients were for rehabilitation centres in 2010 (0.59) and health houses in 2011 (0.12) respectively. Generally, inequalities in the distribution of health care resources were lower at the end of the study period, although there was potential for more equitable distribution of pharmacists, specialists, health houses and beds.

Inégalités relatives dans la répartition géographique des ressources en soins de santé dans la province de Kermânchâh (République islamique d'Iran)

RÉSUMÉ La présente étude visait à évaluer les inégalités dans la répartition géographique des ressources humaines et physiques du secteur de la santé de la province de Kermânchâh (République islamique d'Iran). Dans une étude rétrospective transversale, des données du centre iranien des statistiques ont été exploitées pour calculer des mesures d'inégalité (le coefficient de Gini et l'indice de dissimilitude) entre 2005 et 2011. Le coefficient de Gini le plus élevé pour les ressources humaines a été observé chez les pharmaciens en $2005(0,75)$ et le plus faible chez les personnels paramédicaux en 2010 et 2011 (0,10). Les indices de dissimilitude les plus élevés concernaient aussi les pharmaciens en 2005 (29\%) et les personnels paramédicaux en 2011 (3\%). Pour les ressources physiques, les coefficients de Gini les plus élevés et les plus faibles concernaient les centres de réadaptation en $2010(0,59)$ et les maisons de santé en 2011 (0,12), respectivement. De manière générale, les inégalités dans la répartition des ressources en soins de santé étaient plus faibles à la fin de la période de l'étude, même s'il existait un potentiel pour une répartition plus équitable des pharmaciens, des spécialistes, des maisons de santé et des lits.

${ }^{7}$ Research Centre for Environmental Determinants of Health, Kermanshah University of Medical Sciences, Kermanshah, Islamic Republic of Iran (Correspondence to B.K. Matin: bkmatin1344@gmail.com). 2Department of Health Management and Economics, School of Public Health, Tehran University of Medical Sciences, Tehran, Islamic Republic of Iran. ${ }^{3}$ Amol Imam Reza Hospital, Mazandaran University ofMedical Sciences, Sari, Islamic Republic of Iran.

Received: 08/09/14; accepted: 08/11/15 


\section{Introduction}

Unequal geographical distribution of health care resources has been a persistent policy concern throughout the world (1-6). It is not only a challenge to policy-makers, researchers and planners in the health sector but is also a major barrier to the successful performance of health systems $(1,7,8)$. While there is a positive relationship between the geographical availability of health care resources and the health status of populations, increasing health care resources alone does not necessarily lead to improved health outcomes. People regardless of their race, sex and geographical region should be guaranteed fair access to health care services $(9,10)$.

Previous studies have mainly focused either on inequality in the distribution of health workers or of health care resources $(8,11-16)$. However, sound decisions are dependent on timely and accurate information concerning the distribution all needed health care resources. In the Islamic Republic of Iran, studies conducted over the country as a whole and in Kermanshah province in particular have reported a high rate of unemployment, low income among a significant proportion of the population and low access to health care resources. These conditions may contribute to inequality in the distribution of health care resources (17-20).

Little evidence is available concerning inequality in health care resource distribution in Kermanshah province. Therefore, the aim of this study was to determine whether there were inequalities in the human and physical health care resources distributed across the province during the period 2005 to 2011 and whether was there a time trend in resource distribution. The findings are expected to contribute to evidence-based resource allocation in the province.

\section{Methods}

\section{Context and geographical units of analysis}

Kermanshah province in the west of the Islamic Republic of Iran consists of 14 counties and is bordered by Hamadan, Kurdistan, Lorestan and Ilam provinces in the east, north, south and south of the country respectively and by Iraq in the west. The total population of the province in the year 2014 was estimated to be around 2 million.

\section{Study design and population}

We used a case-study design to describe the distribution of human and physical resources in the province. The data were obtained from the Statistical Centre of Iran (17). The data from each county was summed to represent the resource distribution in the province, and the unit of analysis was the entire province. In addition, the data on distribution of human resources (the number of specialists, general medical practitioners, pharmacists, dentists and paramedics per 1000000 population) and physical resources (the number of health houses, beds, pharmacy, radiology centres, rehabilitation centres and laboratory facilities per 1000000 population) over the years 2005 to 2011 were used to calculate inequality measures for the province.

\section{Inequality measures and data analysis}

There are many indicators to measure inequality in the geographic distribution in health variables, such as the Lorenz curve, Gini coefficient, decile ratio, index of dissimilarity, Atkinson index and Robin Hood index $(4,21)$. We used the Gini coefficient and the index of dissimilarity which are both commonly used in analysing inequality in the distribution of health care resources $(10,22,23)$.

The values of the Gini coefficient vary from 0 (perfect equality) to 1 (perfect inequality). This index can be derived from the Lorenz curve (Figure 1) using the following formula:

$$
\text { Gini coefficient }=A / A+B
$$

Where $\mathrm{A}=$ area between the Lorenz curve and the $45^{\circ}$ line, whole area under the $45^{\circ}$ line.

In the Lorenz curve, the cumulative percentage of the health care resource variables on the $y$-axis and the cumulative percentage of population on the $\mathrm{x}$-axis are shown. The current study used Brown's formula to calculate the Gini coefficient as follows (24):

$$
\text { Gini coefficient }=1-\sum_{i=0}^{k-1}\left(Y_{i+1}+Y_{i}\right)\left(X_{i+1}-X_{i}\right)
$$

Where: $Y i=$ cumulative percentage of health variable in the $\mathrm{i}^{\text {th }}$ county, $X i=\mathrm{cu}$ mulative percentage of the population (ranked by variables) in the $\mathrm{i}^{\text {th }}$ county, $K$ $=$ total number of counties.

The index of dissimilarity indicates the percentage of all health variables that are redistributed across counties to achieve a situation of perfect equality. The value of the index varies between 0 (perfect equality) and 100 (perfect inequality) and is calculated using the following formula (25):

$$
\text { Index of dissimilarity }=\frac{1}{2} \sum_{\mathrm{i}=1}^{\mathrm{n}}\left|\mathrm{x}_{\mathrm{ip}}-\mathrm{x}_{\mathrm{ih}}\right|
$$

Where: $\mathrm{X}_{\mathrm{ip}}=\mathrm{i}^{\text {th }}$ county's population share, $X_{\text {ih }} \stackrel{\text { ip }}{=} \mathrm{i}^{\text {th }}$ county's health variable share, $n=$ total number of counties.

The time trend in inequality of health care resources was examined by estimating 11 regression models, one for each resource. The dependent variable was the Gini coefficient for the resource and the independent variable was the year as follows:

$$
Y=\beta_{0}+\beta_{i} x+\varepsilon_{i}
$$

Where $Y=$ Gini coefficient for $\mathrm{i}^{\text {th }}$ health variable; $x=$ year.

The robust standard error was applied for possible heteroscedasticity over time inferences. Also, the $\beta$ 


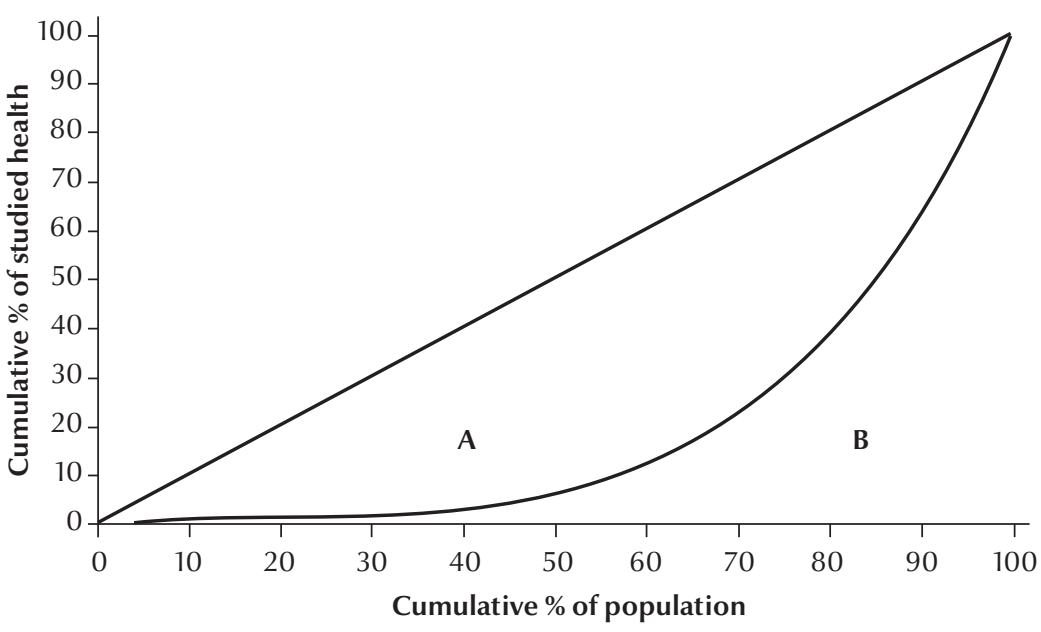

Figure 1 Lorenz curve for derivation of the Gini coefficient

coefficient was used to capture the direction and magnitude of the trend in the Gini for each health variable (3). Negative $\beta$ implies that the Gini coefficient declined over time and the distribution of health variable became more equal.

The data analysis was carried out using Stata, version 12, and DASP, version 2.3 , and the findings were considered statistically significant at $P$-value $<0.05$.

\section{Results}

This study assessed 14 counties in Kermanshah province for inequalities in the distribution of human and physical resources in the health sector.

\section{Human and physical health resources per 1000000 population}

In general there was an increase in the allocated human and physical resources between 2005 and 2011. For example, the number of general practitioners increased from 195 per 1000000 population to 229 per 1000000 between 2005 and 2011, while hospital beds increased from 1141 to 1575 per 1000000 population over the same period (Table 1).

\section{Gini coefficient and index of dissimilarity for distribution of human and physical health care resources}

Table 2 shows the Gini coefficients and indices of dissimilarity for the distribution of human health care resources in Kermanshah province over the years 2005-2011. These demonstrate the presence of inequalities in the health human resources. The highest Gini coefficient was observed for pharmacists in 2005 (0.75) and the lowest was for paramedics in 2010 and $2011(0.10)$. Similarly, analysis by index of dissimilarity showed that in 2005 the highest and lowest index of dissimilarity were for pharmacists (29\%) and for general practitioners $(12 \%)$ respectively, while in 2011 the height and lowest index of dissimilarity were for dentists (19\%) and for paramedics (3\%) respectively.

Generally, a reduction in the inequalities was observed between the baseline and the end of the study. For instance, the Gini coefficient for all types of specialists reduced from 0.39 in 2005 to 0.26 in 2011. Similarly, the Gini coefficient for dentists fell from 0.39 in 2005 to 0.23 in 2010 and 0.32 in 2011.

Table 3 shows the Gini coefficients and indices of dissimilarity for physical health care resources. The highest Gini coefficient was for rehabilitation centres in 2010 (0.59) and the lowest was for health houses in 2011 (0.12). Similarly, the highest index of dissimilarity was for rehabilitation centres in 2010 (36\%) and the lowest was for laboratories in 2007 (5\%).

\section{Time trends in Gini coefficient for distribution of human and physical health care resources}

The time trends in human and physical resources based on Gini coefficients in Kermanshah province over the years 2005-2011 are presented in Figures 2 and 3 respectively.

Although irregularities were seen, between 2006 and 2011 the inequality for the distribution of pharmacists showed a decreasing trend, whereas the inequality for general practitioners was almost constant at a Gini coefficient of about 0.2 and in paramedics it was almost constant at a Gini coefficient of about 0.1 .

Among the physical resources, the distribution of health houses, pharmacies and rehabilitation centres remained almost constant between 2006 and 2011 at different levels of Gini coefficient.

\section{Regression analysis}

Regression analysis indicated that among the human resources there was a statistically significant reduction in inequality in the distribution of pharmacists $(P=0.02)($ Table 4$)$. Among the physical resources, there was a statistically significant reduction in inequality in the distribution of health houses $(P$ $=0.01)$ and of pharmacies $(P=0.004)$. However, the reduction in inequality for rehabilitation centres was borderline in significance $(P=0.06)$.

\section{Discussion}

One of the main objectives of health policy-makers is ensuring fair and equitable distribution of health services. According to the Iranian statistical yearbook, 


\begin{tabular}{|c|c|c|c|c|c|c|c|}
\hline \multirow[t]{2}{*}{ Health resource } & \multicolumn{7}{|c|}{ No. per 1000000 population } \\
\hline & 2005 & 2006 & 2007 & 2008 & 2009 & 2010 & 2011 \\
\hline \multicolumn{8}{|l|}{ Human resources } \\
\hline Specialists & 127 & 117 & 134 & 144 & 143 & 154 & 219 \\
\hline General practitioners & 195 & 176 & 193 & 213 & 221 & 231 & 229 \\
\hline Pharmacists & 13 & 10 & 14 & 14 & 15 & 19 & 21 \\
\hline Dentists & 29 & 33 & 34 & 39 & 41 & 47 & 43 \\
\hline Paramedics & 1093 & 2858 & 3083 & 3122 & 3205 & 3343 & 3373 \\
\hline \multicolumn{8}{|l|}{ Physical resources } \\
\hline Health houses & 352 & 353 & 353 & 353 & 351 & 347 & 340 \\
\hline Hospital beds & 1141 & 1279 & 1302 & 1566 & 1574 & 1582 & 1575 \\
\hline Laboratories & 58 & 51 & 61 & 61 & 65 & 66 & 65 \\
\hline Rehabilitation centres & 26 & 29 & 29 & 30 & 31 & 32 & 32 \\
\hline Radiology centres & 27 & 23 & 29 & 30 & 30 & 36 & 31 \\
\hline Pharmacies & 89 & 94 & 101 & 102 & 97 & 99 & 101 \\
\hline
\end{tabular}

the number of general practitioners, pharmacies, health houses and beds were $14901,8484,17649$ and 103365 per 100000 population respectively in Islamic Republic of Iran in 2011, of which Kermanshah province had 2.9\% of the general practitioners, $2.3 \%$ of pharmacies, $3.7 \%$ of health houses and $2.9 \%$ of beds. According to the 2011 census, $2.5 \%$ of the country's population were in Kermanshah province in 2011. In 2011 on average, there were 233 specialists per 1000000 population in the whole country compared with 219 per 1000000 in Kermanshah province. The number of pharmacies in 2011 was
120 per 1000000 population in the whole country and 101.3 per 1000000 in Kermanshah.

This study has shown inequalities in the distribution of human and physical resources in the province. For human resources the Gini coefficients for specialists, general practitioners, dentists, pharmacists and paramedics were found to closely relate to the reports of other previous studies $(22,26,27)$. However, the Gini coefficient for dentists in this study in 2011 was higher than that was reported from Japan (0.255) (28) and lower than the report from previous study across all provinces in Islamic
Republic of Iran (0.39) (26). This difference may be due to the inclusion of only one province in our study while the others represented entire nations. Also, the previous Iranian study included all dentists practising in the public and private sectors and this will add to the difference in Gini coefficient between the current study and the previous one. The Gini coefficient for general practitioners in our study (0.18) is somewhat higher than the Gini coefficient of 0.14 for the distribution of physicians reported from a study in Turkey. The Gini coefficient reported from Turkey represented all physicians, including specialists,

\begin{tabular}{|c|c|c|c|c|c|c|c|c|c|c|}
\hline \multirow[t]{2}{*}{ Year } & \multicolumn{2}{|c|}{ Specialists } & \multicolumn{2}{|c|}{$\begin{array}{c}\text { General } \\
\text { practitioners }\end{array}$} & \multicolumn{2}{|c|}{ Dentists } & \multicolumn{2}{|c|}{ Pharmacists } & \multicolumn{2}{|c|}{ Paramedics } \\
\hline & Gini (SE) & $\begin{array}{l}\text { ID } \\
\%\end{array}$ & Gini (SE) & $\begin{array}{l}\text { ID } \\
\%\end{array}$ & Gini (SE) & $\begin{array}{l}\text { ID } \\
\%\end{array}$ & Gini (SE) & $\begin{array}{l}\text { ID } \\
\%)\end{array}$ & Gini (SE) & $\begin{array}{l}\text { ID } \\
\%\end{array}$ \\
\hline 2005 & $0.39(0.09)$ & 17 & $0.22(0.02)$ & 12 & $0.39(0.09)$ & 21 & $0.75(0.07)$ & 29 & $0.30(0.07)$ & 12 \\
\hline 2006 & $0.38(0.10)$ & 6 & $0.17(0.07)$ & 5 & $0.24(0.05)$ & 20 & $0.73(0.11)$ & 11 & $0.12(0.03)$ & 3 \\
\hline 2007 & $0.34(0.10)$ & 6 & $0.16(0.03)$ & 5 & $0.23(0.04)$ & 8 & $0.62(0.12)$ & 10 & $0.12(0.02)$ & 4 \\
\hline 2008 & $0.40(0.09)$ & 16 & $0.17(0.02)$ & 10 & $0.21(0.03)$ & 14 & $0.68(0.10)$ & 27 & $0.11(0.02)$ & 4 \\
\hline 2009 & $0.31(0.10)$ & 6 & $0.16(0.03)$ & 12 & $0.24(0.06)$ & 18 & $0.56(0.10)$ & 21 & $0.11(0.03)$ & 4 \\
\hline 2010 & $0.40(0.10)$ & 16 & $0.17(0.03)$ & 13 & $0.23(0.05)$ & 19 & $0.63(0.11)$ & 25 & $0.10(0.02)$ & 4 \\
\hline 2011 & $0.26(0.06)$ & 12 & $0.18(0.03)$ & 14 & $0.32(0.07)$ & 19 & $0.40(0.09)$ & 17 & $0.10(0.02)$ & 3 \\
\hline
\end{tabular}

Gini = Gini coefficient; $I D=$ index of dissimilarity; $S E=$ standard error. 


\begin{tabular}{|c|c|c|c|c|c|c|c|c|c|c|c|c|}
\hline \multirow[t]{2}{*}{ Year } & \multicolumn{2}{|c|}{ Health houses } & \multicolumn{2}{|c|}{ Hospital beds } & \multicolumn{2}{|c|}{ Pharmacies } & \multicolumn{2}{|c|}{ Laboratories } & \multicolumn{2}{|c|}{$\begin{array}{l}\text { Rehabilitation } \\
\text { centres }\end{array}$} & \multicolumn{2}{|c|}{ Radiology centres } \\
\hline & Gini (SE) & $\begin{array}{l}\text { ID } \\
\%\end{array}$ & Gini (SE) & $\begin{array}{l}\text { ID } \\
\%\end{array}$ & Gini (SE) & $\begin{array}{l}\text { ID } \\
\%\end{array}$ & Gini (SE) & $\begin{array}{l}\text { ID } \\
\%\end{array}$ & Gini (SE) & $\begin{array}{l}\text { ID } \\
\%\end{array}$ & Gini (SE) & $\begin{array}{l}\text { ID } \\
\%\end{array}$ \\
\hline 2005 & $0.19(0.04)$ & 29 & $0.47(0.09)$ & 28 & $0.28(0.07)$ & 15 & $0.29(0.07)$ & 12 & $0.43(0.09)$ & 28 & $0.47(0.09)$ & 22 \\
\hline 2006 & $0.15(0.03)$ & 13 & $0.45(0.09)$ & 10 & $0.21(0.05)$ & 5 & $0.22(0.05)$ & 6 & $0.51(0.08)$ & 10 & $0.35(0.08)$ & 9 \\
\hline 2007 & $0.15(0.03)$ & 13 & $0.45(0.09)$ & 10 & $0.17(0.03)$ & 6 & $0.20(0.03)$ & 5 & $0.54(0.10)$ & 9 & $0.22(0.03)$ & 8 \\
\hline 2008 & $0.14(0.03)$ & 30 & $0.46(0.10)$ & 24 & $0.18(0.03)$ & 7 & $0.21(0.05)$ & 13 & $0.48(0.10)$ & 29 & $0.20(0.03)$ & 16 \\
\hline 2009 & $0.13(0.02)$ & 30 & $0.46(0.09)$ & 23 & $0.18(0.06)$ & 10 & $0.18(0.04)$ & 6 & $0.52(0.11)$ & 30 & $0.47(0.09)$ & 25 \\
\hline 2010 & $0.13(0.04)$ & 31 & $0.44(0.10)$ & 24 & $0.21(0.05)$ & 12 & $0.18(0.05)$ & 8 & $0.59(0.12)$ & 36 & $0.22(0.04)$ & 19 \\
\hline 2011 & $0.12(0.01)$ & 30 & $0.40(0.10)$ & 24 & $0.19(0.04)$ & 11 & $0.18(0.04)$ & 8 & $0.44(0.09)$ & 18 & $0.23(0.04)$ & 27 \\
\hline
\end{tabular}

Gini = Gini coefficient; $I D=$ index of dissimilarity; $S E=$ standard error

however, and this implies lower inequality than in our study (27).

In this study, the distribution of resources was also analysed using the index of dissimilarity. For human resources the index of dissimilarity for dentists was 19\%, which implies that $19 \%$ of the currently available dentists in the province could be redistributed from the over-served counties to the relatively under-served areas across the province to reach an equitable distribution. The index of dissimilarity for dentists in the current study is lower than that reported for dentists (30.5\%) in the previous
Iranian study (26). As mentioned above, that study considered all dentists, both private and public, and this could be a likely reason for this difference.

In our study time-trend analysis showed inequalities in the distribution of all human and physical resources decreased from baseline in the year 2005 to 2011. Although the findings showed a reduction in the inequality in the distribution of health resources, regression analysis showed that the reductions were statistically significant only pharmacists, health houses and pharmacies. The reasons could be related to the emphasis given to the development of primary health care in areas where the public have unmet health care services (29).

Although inequalities still exist, the improvement in the distribution of the health care resources over the 7 -year period of our study may imply that Iranian health sector policy-makers have paid attention to improving the allocation of resources across the country. Besides, the increase in the number of specialists, general medical practitioners and pharmacists between the years 2005 and 2011 may indicate that the government

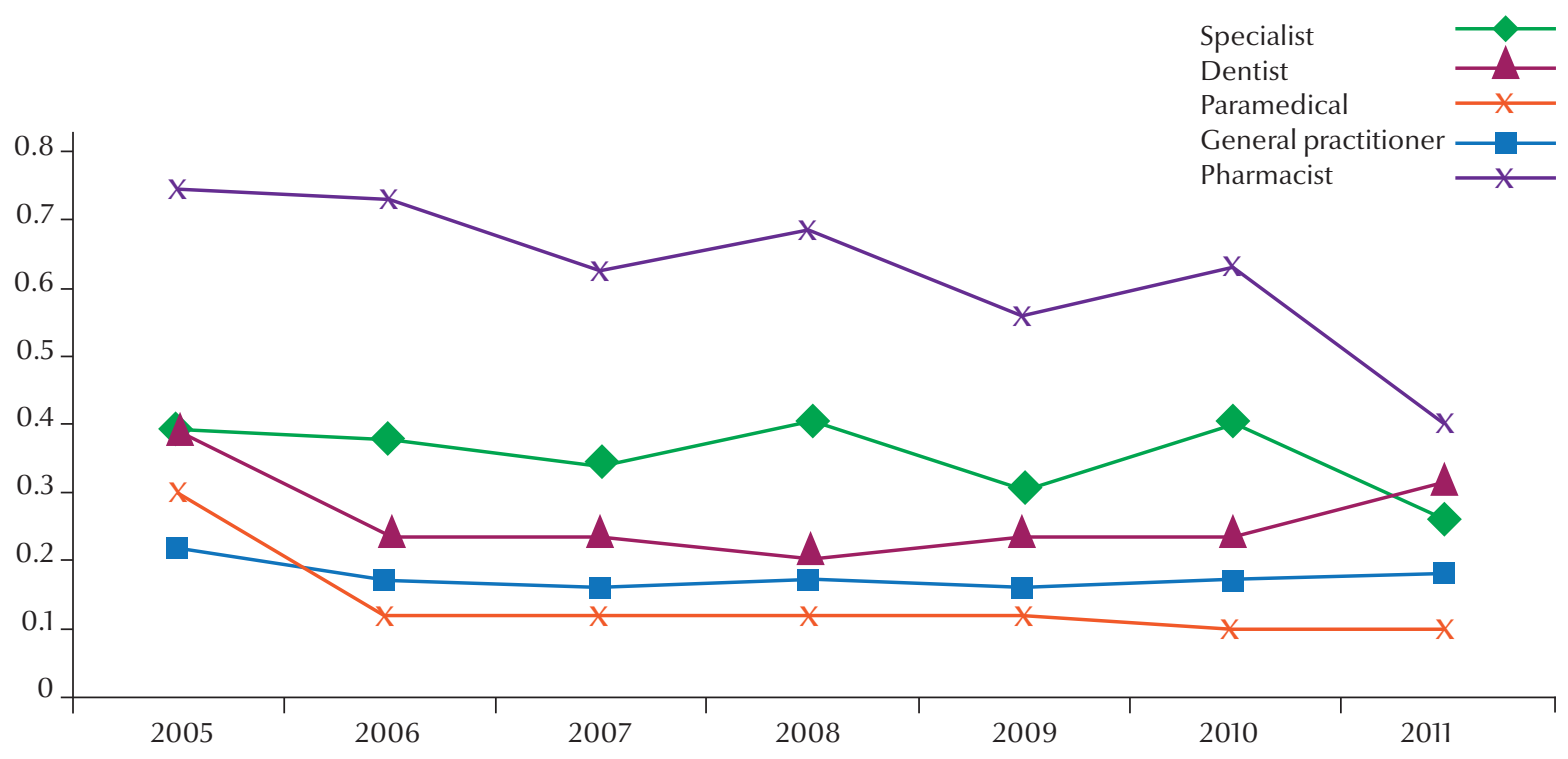

Figure 2 Trends in the Gini coefficient for the distribution of human resources in Kermanshah province, 2005-2011 


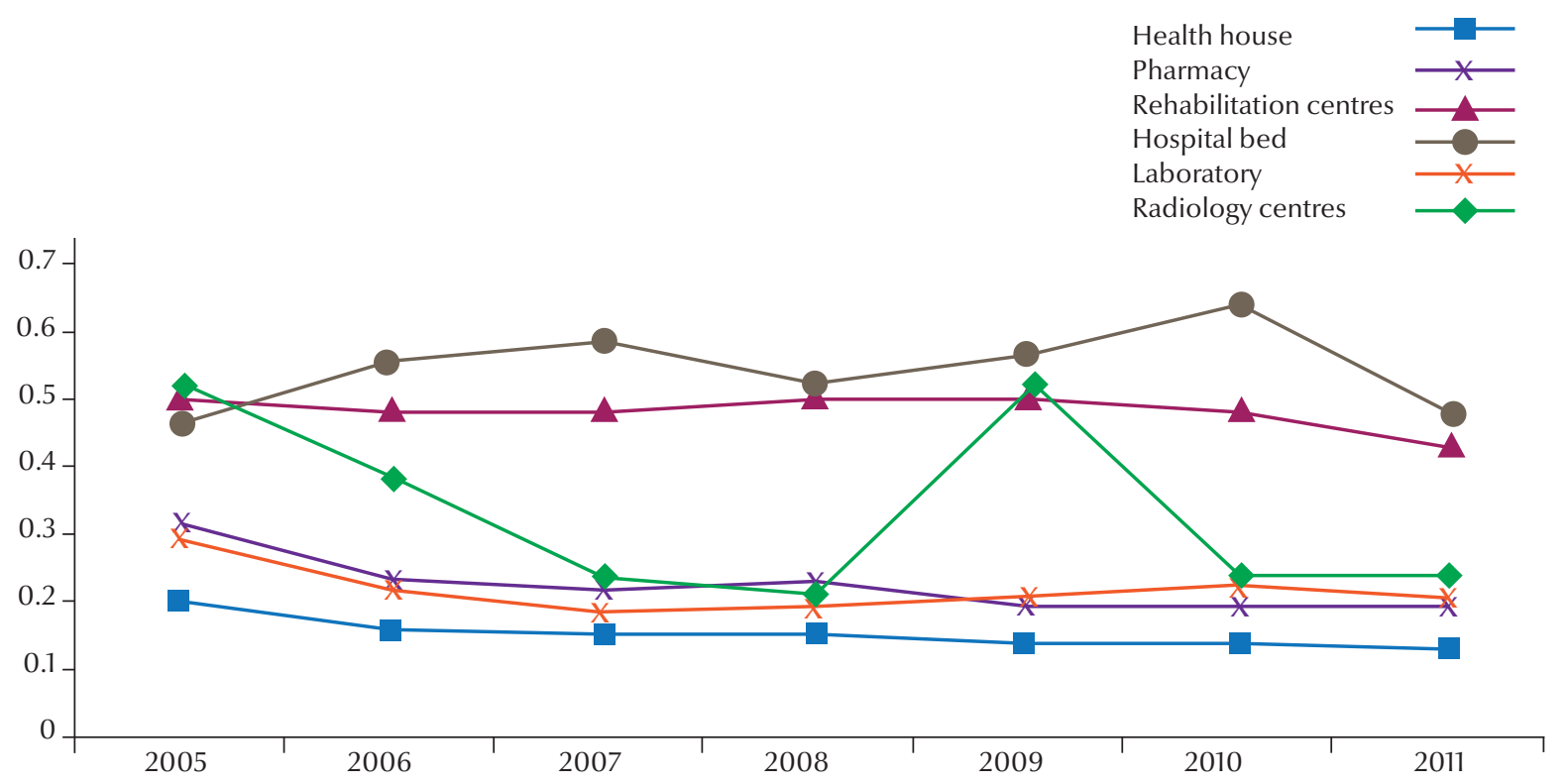

Figure 3 Trends in the Gini coefficient for the distribution of physical resources in Kermanshah province, 2005-2011

has paid more attention to the production of these human resources. The increase in the percentage of these distributed resources was higher than the population growth, which showed only a $4 \%$ increase between the beginning and end of the study period. A government regulation which allows new graduate general practitioners, dentists, pharmacists and other health professionals to work in remote areas seems to have contributed to the reduction in inequality in the distribution of human resources for health.

A previous study also reported that improvement in roads and transportation systems and incentives and promotion opportunities to health workers has contributed to reducing inequalities in the distribution of resources for health (22). Other reasons could have due to improvement in the equity of distribution of health care resources. However, this study focused only on the distribution of public health resources across the province. The private sector is usually known to practise in areas where it can generate profit from the delivery of services. It has been reported that in Islamic
Republic of Iran about $80 \%$ of dentists are working in the private sector in urban areas (30).

This study focused on analysis of inequality in the distribution of human and physical resources. The fact that the data were credible and representative of the province helps us to confidently characterize the magnitude

of inequality in the distribution of human and physical resources in Kermanshah and to suggest possible solutions. However, this analysis did not include the opinion of the people in the province concerning the distribution of the resources analysed. Hence, obtaining additional information from the direct beneficiaries of

Table 4 Regression analysis of time trends of inequality in the distribution of human and physical health resources in Kermanshah province over the years 2005-2011

\begin{tabular}{|c|c|c|c|}
\hline Health resource & $\beta$-coefficient & t-statistic & $\begin{array}{c}P \text {-value } \\
\text { (robust SE) }\end{array}$ \\
\hline \multicolumn{4}{|l|}{ Human resources } \\
\hline Specialists & -0.013 & -1.45 & 0.2 \\
\hline General practitioners & -0.004 & -0.89 & 0.4 \\
\hline Pharmacists & -0.04 & -3.36 & 0.02 \\
\hline Paramedics & -0.02 & -1.69 & 0.15 \\
\hline Dentists & -0.007 & -0.047 & 0.6 \\
\hline \multicolumn{4}{|l|}{ Physical resources } \\
\hline Health houses & -0.009 & -3.56 & 0.01 \\
\hline Hospital beds & +0.006 & 0.43 & 0.68 \\
\hline Pharmacies & -0.015 & -2.85 & 0.004 \\
\hline Laboratories & -0.009 & -1.29 & 0.25 \\
\hline Rehabilitation centres & -0.007 & -2.33 & 0.06 \\
\hline Radiology centres & -0.02 & -1.81 & 0.13 \\
\hline
\end{tabular}

$S E=$ standard error. 
the services and health care managers in the area could consolidate the findings. In addition, the study was limited to the distribution of health care resources in Kermanshah province, and therefore the findings cannot be generalized to other provinces in the Islamic Republic of Iran.

\section{Conclusions}

The results show that inequalities in the distribution of health care resources between the years 2005 and 2011 have decreased, although there was still a potential for more equitable distribution of some resources, such as pharmacists, specialists, health houses and beds, which could be done by the redistribution of the already available resources or by increasing the total resources.

Funding: This study was funded by Kermanshah University of Medical Sciences. Competing interests: None declared.

\section{References}

1. Nishiura H, Barua S, Lawpoolsri S, Kittitrakul C, Leman MM, Maha MS, et al. Health inequalities in Thailand: geographic distribution of medical supplies in the provinces. Southeast Asian J Trop Med Public Health. 2004 Sep;35(3):735-40. PMID:15689097

2. Hann M, Gravelle H. The maldistribution of general practitioners in England and Wales: 1974-2003. Br J Gen Pract. 2004 Dec;54(509):894-8. PMID:15588532

3. Horev T, Pesis-Katz I, Mukamel DB. Trends in geographic disparities in allocation of health care resources in the US. Health Policy. 2004 May;68(2):223-32. PMID:15063021

4. Theodorakis PN, Mantzavinis GD. Inequalities in the distribution of rural primary care physicians in two remote neighboring prefectures of Greece and Aolbania. Rural Remote Health. 2005 Jul-Sep;5(3):457. PMID:16134954

5. Isabel C, Paula V. Geographic distribution of physicians in Portugal. Eur J Health Econ. 2010 Aug;11(4):383-93. PMID:20012127

6. Shahabi M, Tofighi Sh, Malaki MR. The nurse and specialist physicians manpower distribution by population and its relationship with the number of beds at public hospitals in Iran 2001-2006. Journal of Health Administration. 2010;41(13):1-5.

7. Berndt DJ, Fisher JW, Rajendrababu RV, Studnicki J. Measuring healthcare inequities using the Gini index. In: Proceedings of the 36th Annual Hawaii International Conference on System Sciences. Track 6, Volume 6. Washington (DC): Institute of Electrical and Electronics Engineers Computer Society; 2003.

8. Gravelle H, Sutton M. Inequality in the geographical distribution of general practitioners in England and Wales 1974-1995. J Health Serv Res Policy. 2001 Jan;6(1):6-13. PMID:11219363

9. Taylor DH; Ricketts TC, Kolimaga J. Defining under-service and physician shortage areas in historical and future context. North Carolina Rural Health Research Program Working Paper No.30. Chapel Hill (NC): Cecil G. Sheps Center for Health Services Research, University of North Carolina; 1994.

10. Ahmad Kiadaliri A, Najafi B, Haghparast-Bidgoli H. Geographic distribution of need and access to health care in rural population: an ecological study in Iran. Int J Equity Health. 2011;10(1):39. PMID:21939511

11. Mantzavinis G, Theodorakis PN, Lionis C, Trell E. Geografiska ojamlikheter i Sverige i fordelningen av allmanlakare. [Geographical inequalities in the distribution of general practitioners in Sweden]. Lakartidningen. 2003 Dec 18;100(5152):4294-7. PMID:14756094

12. Munga MA, Maestad O. Measuring inequalities in the distribution of health workers: the case of Tanzania. Hum Resour Health. 2009;7(1):4. PMID:19159443

13. Taati Keley E, Meshkini A, Zavareh DK. Distribution of specialists in public hospitals of Iran. Health Inf Manag. 2012;9(4):54857.
14. Nedjat S, Hosseinpoor AR, Forouzanfar MH, Golestan B, Majdzadeh R. Decomposing socioeconomic inequality in selfrated health in Tehran. J Epidemiol Community Health. 2012 Jun;66(6):495-500. PMID:21282143

15. Mobaraki H, Hassani A, Kashkalani T, Khalilnejad R, Chimeh EE. Equality in distribution of human resources: the case of Iran's Ministry of Health and Medical Education. Iran J Public Health. 2013;42 Suppl 1:161-5. PMID:23865035

16. Omrani-Khoo H, Lotfi F, Safari H, Zargar Balaye Jame S, Moghri J, Shafii M. Equity in distribution of health care resources; assessment of need and access, using three practical indicators. Iran J Public Health. 2013 Nov; 42(11):1299-308. PMID:26171343

17. Statistical Centre of Iran [Internet]. (http://www.amar.org.ir/ Default.aspx?tabid=1649, accessed 26 November 2015).

18. Mousavi S, Seyedin S, Aryankhesal A, Sadeghifar J, Armoun B, Safari $Y$, et al. Stratification of Kermanshah province districts in terms of health structural indicators using scalogram model. J Healthc Prot Manage. 2013;2(2):7-15.

19. Rezaei S, Ghazanfari S, Kazemi Z, Karyani AK. Access to healthcare facilities: case study of Kermanshah province [in Persian]. Journal of Kermanshah University of Medical Sciences. 2014;18(7):416-25.

20. Sulaimany A, Ghadiri Masum M, Riahi V. The development level of health indicators in Kermanshah province from the perspective of social justice in 2010 [in Persian]. Journal of Kermanshah University of Medical Sciences. 2014;17(10):647-56.

21. Schneider MC, Castillo-Salgado C, Bacallao J, Loyola E, Mujica OJ, Vidaurre $M$, et al. Methods for measuring health inequalities (Part III). Epidemiol Bull. 2005 Jun;26(2):12-5. PMID:16578883

22. Theodorakis PN, Mantzavinis GD, Rrumbullaku L, Lionis C, Trell E. Measuring health inequalities in Albania: a focus on the distribution of general practitioners. Hum Resour Health. 2006;4(1):5. PMID:16504028

23. Chang RKR, Halfon N. Geographic distribution of pediatricians in the United States: an analysis of the fifty states and Washington, DC. Pediatrics. 1997 Aug;100(2 Pt 1):172-9. PMID:9240795

24. Brown MC. Using Gini-style indices to evaluate the spatial patterns of health practitioners: theoretical considerations and an application based on Alberta data. Soc Sci Med. 1994 May;38(9):1243-56. PMID:8016689

25. Wagstaff A, Paci P, van Doorslaer E. On the measurement of inequalities in health. Soc Sci Med. 1991;33(5):545-57. PMID:1962226

26. Kiadaliri AA, Hosseinpour R, Haghparast-Bidgoli H, Gerdtham U-G. Pure and social disparities in distribution of dentists: a cross-sectional province-based study in Iran. Int J Environ Res Public Health. 2013 May;10(5):1882-94. PMID:23648443 
27. Yardım MS, Üner S. Geographical disparities in the distribution of physicians in Turkey. TAF Preventive Medicine Bulletin. 2013;12(5):487-94.

28. Okawa Y, Hirata S, Okada M, Ishii T. Geographic distribution of dentists in Japan: 1980-2000. J Public Health Dent. 2011 Summer;71(3):236-40. PMID:21972464
29. Hall JJ, Taylor R. Health for all beyond 2000: the demise of the Alma-Ata Declaration and primary health care in developing countries. Med J Aust. 2003 Jan 6;178(1):17-20. PMID:12492384

30. Hosseinpoor AR, Itani L, Petersen PE. Socio-economic inequality in oral healthcare coverage: results from the World Health Survey. J Dent Res. 2012 Mar;91(3):275-81. PMID:22205634 